Research Article

\title{
Optimal Ordering Policy for Supply Option Contract with Spot Market
}

\author{
Xinru Hou, ${ }^{1}$ Xinsheng $\mathrm{Xu}^{2}{ }^{2}$ and Haibin Chen ${ }^{1}{ }^{1}$ \\ ${ }^{1}$ School of Management Science, Qufu Normal University, Rizhao, Shandong, China \\ ${ }^{2}$ College of Science, Binzhou University, Binzhou, Shandong, China \\ Correspondence should be addressed to Haibin Chen; chenhaibin508@qfnu.edu.cn
}

Received 19 October 2020; Revised 19 November 2020; Accepted 23 November 2020; Published 9 December 2020

Academic Editor: Zeshui Xu

Copyright (c) 2020 Xinru Hou et al. This is an open access article distributed under the Creative Commons Attribution License, which permits unrestricted use, distribution, and reproduction in any medium, provided the original work is properly cited.

This paper considers the procurement mechanism with two supply channels, namely, an option contract purchase and a spot market. For the mechanism, under the stochastic demand and the stochastic spot price, we consider the portfolio procurement with the spot trading liquidity and the option speculation respectively. To maximize the buyer's profit, we establish two optimal portfolio procurement strategy models for those two scenarios. Based on the buyer's cost-benefit analysis, we present a solution method to each model and provide an optimal ordering policy to the buyer. By the obtained results, we analyze the role of the spot trading liquidity and option speculation in a buyer's expected profit. Some numerical experiments are presented to show the validity of the formulated models.

\section{Introduction}

As an important supplement to the e-commerce, the spot market with the stochastic spot price plays an important role in commodity trading. For instance, in China, there are more than 200 spot markets providing spot trading of bulk commodities, and up to $60 \%$ of iron ore is purchased from the spot market [1]. In the United States, about 30\% of memory chip and $60 \%$ of meat packing are purchased from the spot market [2], see e.g., [3] for a comprehensive review on spot market.

Although the spot market provides a flexible channel for trading of commodities, the stochastic of spot price and the liquidity of spot trading make the spot market unreliable. Compared with the spot market, supply contract, i.e., longtime contract or option contract, can guarantee the stability of the supply to buyer. Nevertheless, the supply contract has the risk caused by demand uncertainty. As a consequence, the portfolio procurement strategy which combines the supply contract and spot market is generated to cope with the stochastic demand and the stochastic spot price. It is reported that the Hewlett-Packard (HP) engaged the portfolio procurement with the option contract and spot market to meet the demand, and its portfolio procurement had saved HP over \$425 million from 2000 to 2006 [4].

As for the research of the portfolio procurement with spot market, there are mainly two streams, one is on the long-time contract with spot market and the other is on the option contract with spot market. For the first stream, Peleg and Lee [5] compared three procurement strategies based on the buyer's expected cost minimization: a long-term strategy; a short-term strategy based on spot market; and a portfolio procurement strategy of the both. Chen and Liu [6] compared two procurement strategies: single long-term contract and the portfolio procurement with the long-term and the spot market and showed that the portfolio procurement can generate a higher buyer's profit than the single long-term contract. Goel and Gutierrez [7] considered the portfolio procurement and distribution policies for a firm and indicated that the portfolio procurement leads to significant reductions in inventory-related costs. Lee et al. [8] considered the portfolio procurement with the significant demand and spot price volatility and showed that the profit is higher for the spot market than for the long-time contract. Chen et al. [9] considered the portfolio procurement with a stochastic inventory, wherein prices follow a Markov 
process. Adilov [10] considered the portfolio procurement from the perspective of the supplier. Inderfurth et al. [11] considered the multiperiod portfolio procurement with the short-term procurement of the spot market and the capacity reservation of the long-time contract, and so on [12-17].

For the second stream, Fu et al. [18] showed that the portfolio procurement strategy is superior to the single option contract or the spot market procurement strategy. Pei et al. [19] considered the portfolio procurement with volume discounts and volume premia and provided links between production and spot market characteristics, contract design, and efficiency. Zhao et al. [20] considered a two-stage portfolio procurement with the demand information updating. Merzifonluoglu [21, 22] studied the portfolio procurement with a special case that the demand obeys normal distribution. Luo and Chen [23] considered a singleperiod supplier-manufacturer portfolio procurement where the supplier is with a stochastic yield. Lee et al. [24] considered a multisupplier portfolio procurement with capacity constraints. Wan and Chen [25] considered the multiperiod and dual-sourcing replenishment portfolio procurement, and so on [26-31].

The above research assumes that the spot market is only used as a one-way trading channel for the buyer to buy purchase. Nevertheless, in practice, the buyer's exceeded products can be sold in the spot market to make speculation revenue. In addition, the spot market is imperfect because of the spot trading liquidity. In this paper, under the stochastic demand and the stochastic spot price, we, respectively, consider the spot market with the spot trading liquidity and with the option speculation. For this setting, to maximize the buyer's profit, we construct two optimal portfolio procurement strategy models. By analyzing the buyer's costbenefit, we obtain a solution method for each model and provide an optimal ordering policy to the buyer. The role of the spot trading liquidity and option speculation in buyer's expected profit is analyzed, and the cost threshold and option pricing formula are obtained, which provide a decision basis for the buyer.

The remainder of this paper is organized as follows. In Sections 2 and 3, we, respectively, consider the portfolio procurement strategy model with the spot trading liquidity, and the portfolio procurement strategy model with the option speculation. Numerical experiments are presented in Section 4 to illustrate the validity of our research. Some conclusions are drawn in the last section.

\section{The Portfolio Procurement with the Spot Trading Liquidity}

In this section, under the stochastic demand and the stochastic spot price, we consider the portfolio procurement with the spot trading liquidity, that is, the buyer orders by the option contract and the spot market with the spot trading liquidity. For the concerned procurement system, we present the running pattern of it: before the selling season arrives, the buyer signs an option ordering quantity $q$ units with the supplier by prepaying an option purchase price $b$ for each unit based on the estimated stochastic demand during the selling season, and when the selling season comes, we assume that the realized demand and spot price can be determined. Then, the buyer can purchase any units up to the option level $q$ by paying an option execution price $e$ for each unit. In this sense, if the spot price in the spot market is higher than the option execution price, then the buyer will execute the options, and if the realized demand exceeds the option level $q$, the buyer will purchase the products from the spot market and vice versa. It is supposed that the spot capacity is $Q_{s}$. Besides, there is a spot trading liquidity $\gamma \in[0,1]$, which defines the percentage of the products that can be traded for all the products in the spot market, i.e., the buyer can purchase the products no more than $\gamma Q_{s}$ from the spot market. If the realized market demand exceeds the sum of the option level and spot capacity, there will be a shortage penalty $s$ for each lost sale. For this system, to maximize the buyer's profit, the buyer should make an optimal portfolio procurement strategy. To this end, we need some notations which are listed in Table 1.

The assumptions on the concerned model are as follows.

\section{Assumption 1}

(a) The sum of the option purchase price and option execution price is lower than the sum of the retail price and shortage price, i.e., $b+e \leq r+s$

(b) The spot price is lower than the sum of the retail price and shortage price, i.e., $p \leq r+s$

(c) The demand of the items during the selling season obeys the distribution with probability density function $f_{1}(x)$ and distribution function $F_{1}(x)$

(d) The spot price of the items during the selling season obeys the distribution with probability density function $f_{2}(y)$ and distribution function $F_{2}(y)$, and its expected value is $\bar{p}$

For convenience, we use $\Pi_{1}^{o}(q, D)$ to denote the profit from the option contract, and $\Pi_{1}^{s}(q, D, p)$ to denote the profit from the spot market and the shortage penalty for lost sales. According to the assumptions and the principle of the buyer's profit maximization, we can formulate the optimal portfolio procurement strategy model as the following optimization problem:

$$
\max _{q} \Pi_{1}=\Pi_{1}^{o}(q, D)+\Pi_{1}^{s}(q, D, p) .
$$

For the concerned model, if the buyer does not execute the options during the selling season, he/she will lose the option purchase price per unit, and when the selling season comes, the stochastic demand and the stochastic spot price can be determined. So, one of the following three cases will happen:

Case 1. $0 \leq D<q+\gamma Q_{s}$ and $p>e$. In this case, the buyer will first execute the options of $\min (q, D)$ units by paying an option execution price $e$ for each unit, and then the exceeded demand $(D-q)_{+}$will be purchased at the spot price $p$ for each unit from the spot market. Under this case, we have 
TABLE 1: Notations.

\begin{tabular}{lc}
\hline Notation & Description \\
\hline$r$ & Retail price \\
$b$ & Option purchase price \\
$e$ & Option execution price \\
$s$ & Shortage cost \\
$Q_{s}$ & The maximum capacity of the spot market \\
$\gamma$ & The spot trading liquidity \\
$D$ & The stochastic demand \\
$p$ & The stochastic spot price \\
$q$ & Option ordering quantity \\
$E\left[\Pi_{1}(\cdot)\right]$ & Expected profit with the spot trading liquidity \\
$E\left[\Pi_{2}(\cdot)\right]$ & Expected profit with the option speculation \\
\hline
\end{tabular}

$\Pi_{1}^{o}(q, D)=-b q+(r-e) \min (q, D)$, and $\Pi_{1}^{s}(q, D, p)=$ $(r-p)(D-q)_{+}$.
Case 2. $0 \leq D<q+\gamma Q_{s}$ and $p \leq e$. In this case, the buyer will first purchase $\min \left(\gamma Q_{s}, D\right)$ units from the spot market, and then the exceeded demand $\left(D-\gamma Q_{s}\right)_{+}$will be satisfied through options. Under this case, we have $\Pi_{1}^{o}(q, D)=-b q+(r-e)\left(D-\gamma Q_{s}\right)_{+}$, and $\Pi_{1}^{s}(q, D, p)$ $=(r-p) \min \left(\gamma Q_{s}, D\right)$.

Case 3. $D \geq q+\gamma Q_{s}$. In this case, regardless of $p>e$ or $p \leq e$, the buyer will execute the options of $q$ units and purchase $\gamma Q_{s}$ units from the spot market and pay the shortage penalty $s$ for each lost sale. Under this case, we have $\Pi_{1}^{o}(q, D)=(r-e-b) q, \quad$ and $\Pi_{1}^{s}(q, D, p)=(r-p) \gamma Q_{s}-s\left(D-q-\gamma Q_{s}\right)$.

From the analysis above, we can see that the buyer's profit for option ordering quantity $q$ is

$$
\Pi_{1}(q)=-b q+ \begin{cases}(r-e) \min (q, D)+(r-p)(D-q)_{+}, & 0 \leq D<q+\gamma Q_{s}, p>e \\ (r-e)\left(D-\gamma Q_{s}\right)_{+}+(r-p) \min \left(\gamma Q_{s}, D\right), & 0 \leq D<q+\gamma Q_{s}, p \leq e \\ (r-e) q+(r-p) \gamma Q_{s}-s\left(D-q-\gamma Q_{s}\right), & D \geq q+\gamma Q_{s} .\end{cases}
$$

Considering the stochastic of the demand and the spot price, to solve problem (1), we compute the expectation of the buyer's profit. From this, the buyer's expected profit for ordering quantity $q$ in the option contract is

$$
\begin{aligned}
E\left[\Pi_{1}(q)\right]= & -b q \\
& +\int_{e}^{r+s}(r-e) f_{2}(y) \mathrm{d} y \int_{0}^{q} x f_{1}(x) \mathrm{d} x+\int_{e}^{r+s}(r-e) f_{2}(y) \mathrm{d} y \int_{q}^{q+\gamma Q_{s}} q f_{1}(x) \mathrm{d} x \\
& +\int_{e}^{r+s}(r-y) f_{2}(y) \mathrm{d} y \int_{q}^{q+\gamma Q_{s}}(x-q) f_{1}(x) \mathrm{d} x \\
& +\int_{0}^{e}(r-y) f_{2}(y) \mathrm{d} y \int_{0}^{\gamma Q_{s}} x f_{1}(x) \mathrm{d} x+\int_{0}^{e}(r-y) f_{2}(y) \mathrm{d} y \int_{\gamma Q_{s}}^{q+\gamma Q_{s}} \gamma Q_{s} f_{1}(x) \mathrm{d} x \\
& +\int_{0}^{e}(r-e) f_{2}(y) \mathrm{d} y \int_{\gamma Q_{s}}^{q+\gamma Q_{s}}\left(x-\gamma Q_{s}\right) f_{1}(x) \mathrm{d} x \\
& +(r-e) \int_{q+\gamma Q_{s}}^{\infty} q f_{1}(x) \mathrm{d} x+(r-\bar{p}) \int_{q+\gamma Q_{s}}^{\infty} \gamma Q_{s} f_{1}(x) \mathrm{d} x-s \int_{q+\gamma Q_{s}}^{\infty}\left(x-q-\gamma Q_{s}\right) f_{1}(x) \mathrm{d} x .
\end{aligned}
$$

The first term in the right-hand side is the cost of purchasing the options of $q$ units before the selling season, the second to the fourth items represent the retail revenue of the buyer for the case that $0 \leq D<q+\gamma Q_{s}$ and $p>e$, the fifth to the seventh items represent the retail revenue of the buyer for the case that $0 \leq D<q+\gamma Q_{s}$ and $p \leq e$, and the last three items represent the retail revenue and shortage cost of the buyer for the case that $D \geq q+\gamma Q_{s}$.

By maximizing the buyer's profit, we can obtain the optimal ordering policy. 
Theorem 1. The optimal option ordering quantity $q_{1}^{*}$ to maximize the buyer's expected profit $E\left[\Pi_{1}(q)\right]$ satisfies

$$
\begin{aligned}
& r-e-b+s-\left[F_{1}\left(q_{1}^{*}+\gamma Q_{s}\right)-F_{1}\left(q_{1}^{*}\right)\right] \int_{e}^{r+s} F_{2}(y) \mathrm{d} y \\
& -F_{1}\left(q_{1}^{*}\right)(r+s-e)=0 .
\end{aligned}
$$

Proof. For (3), it can be readily computed that

$$
\begin{gathered}
\frac{\partial E\left[\Pi_{1}(q)\right]}{\partial q}=r-e-b+s-\left[F_{1}\left(q+\gamma Q_{s}\right)-F_{1}(q)\right] \int_{e}^{r+s} F_{2}(y) \mathrm{d} y-F_{1}(q)(r+s-e), \\
\frac{\partial^{2} E\left[\Pi_{1}(q)\right]}{\partial q^{2}}=-\left[f_{1}\left(q+\gamma Q_{s}\right)-f_{1}(q)\right] \int_{e}^{r+s} F_{2}(y) \mathrm{d} y-f_{1}(q)(r+s-e) \leq 0,
\end{gathered}
$$

which implies $E\left[\Pi_{1}(q)\right]$ is concave in $q$. From the first-order optimality condition, we conclude that $E\left[\Pi_{1}(q)\right]$ achieves its maximum when $q_{1}^{*}$ satisfies

$$
\begin{aligned}
& r-e-b+s-\left[F_{1}\left(q_{1}^{*}+\gamma Q_{s}\right)-F_{1}\left(q_{1}^{*}\right)\right] \int_{e}^{r+s} F_{2}(y) \mathrm{d} y \\
& -F_{1}\left(q_{1}^{*}\right)(r+s-e)=0 .
\end{aligned}
$$

For the optimal option ordering quantity given in the above conclusion, we have the following properties.

Corollary 1. The buyer's optimal option ordering quantity $q_{1}^{*}$ is increasing w.r.t. the retail price $r$ and the shortage cost $s$.

Proof. From (4), we can obtain that

$$
\begin{aligned}
& \frac{\partial q_{1}^{*}}{\partial r}=\frac{1-F_{1}\left(q_{1}^{*}+\gamma Q_{s}\right)}{\left[f_{1}\left(q_{1}^{*}+\gamma Q_{s}\right)-f_{1}\left(q_{1}^{*}\right)\right] \int_{e}^{r+s} F_{2}(y) d y+f_{1}\left(q_{1}^{*}\right)(r+s-e)} \geq 0, \\
& \frac{\partial q_{1}^{*}}{\partial s}=\frac{1-F_{1}\left(q_{1}^{*}+\gamma Q_{s}\right)}{\left[f_{1}\left(q_{1}^{*}+\gamma Q_{s}\right)-f_{1}\left(q_{1}^{*}\right)\right] \int_{e}^{r+s} F_{2}(y) d y+f_{1}\left(q_{1}^{*}\right)(r+s-e)} \geq 0,
\end{aligned}
$$

which implies $q_{1}^{*}$ is increasing w.r.t. the retail price and shortage cost.

From the conclusion, when retail price $r$ increases, the buyer will have a larger retail revenue and underpurchasing loss; when the shortage cost $s$ increases, the buyer will have a larger underpurchasing loss. From this, to reduce the underpurchasing loss, the buyer will order more options. In addition, when the retail price $r$ or shortage cost $s$ increases, the option purchase price $b$ is relatively low. At this time, the buyer will order more options, and when the selling season comes, the buyer will choose a favorable purchase channel according to the spot price and option execution price. This increases the advantages of the option contract. So, when the retail price $r$ or shortage cost $s$ increases, the buyer should order more options.

Corollary 2. The buyer's optimal option ordering quantity $q_{1}^{*}$ is decreasing w.r.t. the option purchase price $b$, the option execution price $e$, and the spot trading liquidity $\gamma$.

Proof. From (4), we can obtain that

$$
\begin{aligned}
& \frac{\partial q_{1}^{*}}{\partial b}=\frac{-1}{\left[f_{1}\left(q_{1}^{*}+\gamma Q_{s}\right)-f_{1}\left(q_{1}^{*}\right)\right] \int_{e}^{r+s} F_{2}(y) \mathrm{d} y+f_{1}\left(q_{1}^{*}\right)(r+s-e)} \leq 0, \\
& \frac{\partial q_{1}^{*}}{\partial e}=\frac{-1+\left[F_{1}\left(q_{1}^{*}+\gamma Q_{s}\right)-F_{1}\left(q_{1}^{*}\right)\right] F_{2}(e)+F_{1}\left(q_{1}^{*}\right)}{\left[f_{1}\left(q_{1}^{*}+\gamma Q_{s}\right)-f_{1}\left(q_{1}^{*}\right)\right] \int_{e}^{r+s} F_{2}(y) \mathrm{d} y+f_{1}\left(q_{1}^{*}\right)(r+s-e)}, \\
& \leq \frac{F_{1}\left(q_{1}^{*}+\gamma Q_{s}\right)-1}{\left[f_{1}\left(q_{1}^{*}+\gamma Q_{s}\right)-f_{1}\left(q_{1}^{*}\right)\right] \int_{e}^{r+s} F_{2}(y) \mathrm{d} y+f_{1}\left(q_{1}^{*}\right)(r+s-e)} \leq 0, \\
& \frac{\partial q_{1}^{*}}{\partial \gamma}=\frac{-Q_{s} f_{1}\left(q_{1}^{*}+\gamma Q_{s}\right) \int_{e}^{r+s} F_{2}(y) \mathrm{d} y}{\left[f_{1}\left(q_{1}^{*}+\gamma Q_{s}\right)-f_{1}\left(q_{1}^{*}\right)\right] \int_{e}^{r+s} F_{2}(y) \mathrm{d} y+f_{1}\left(q_{1}^{*}\right)(r+s-e)} \leq 0,
\end{aligned}
$$

which implies the assertion holds.

From the conclusion, we can see that when the option purchase price $b$ or option execution price $e$ increases, the buyer will have a larger overpurchasing loss and a lower retail revenue. From this, to reduce the overpurchasing loss, the buyer will order fewer options. When the spot trading liquidity $\gamma$ increases, the buyer will purchase more products from the spot market and order fewer options to reduce the over-ordering cost. 
To gain more insights, we study the effect of the spot trading liquidity $\gamma$ on the buyer's maximum expected profit $E\left[\Pi_{1}\left(q_{1}^{*}\right)\right]$.
Corollary 3. The buyer's maximum expected profit $E\left[\Pi_{1}\left(q_{1}^{*}\right)\right]$ is increasing w.r.t. the spot trading liquidity $\gamma$.

Proof. From (3) and (4), we can obtain that

$$
\frac{\partial E\left[\Pi_{1}\left(q_{1}^{*}\right)\right]}{\partial \gamma}=Q_{s}\left[F_{1}\left(q_{1}^{*}+\gamma Q_{s}\right)-F_{1}\left(\gamma Q_{s}\right)\right] \int_{0}^{e}(e-y) f_{2}(y) d y+(r-\bar{p}+s) Q_{s}\left[1-F_{1}\left(q_{1}^{*}+\gamma Q_{s}\right)\right] \geq 0
$$

which implies the assertion holds.

From the conclusion, we can see that if there is a larger spot trading liquidity, the buyer can purchase more products from the spot market. In addition, the buyer's optimal option ordering quantity $q_{1}^{*}$ is decreasing w.r.t. the spot trading liquidity $\gamma$. That is to say, the increase of $\gamma$ helps the buyer increase the retail revenue and reduce the over-ordering loss. So, the buyer's maximum expected profit $E\left[\Pi_{1}\left(q_{1}^{*}\right)\right]$ is increasing w.r.t. the spot trading liquidity.

\section{The Portfolio Procurement with the Option Speculation}

For the portfolio procurement with the option speculation, when the demand is satisfied, the buyer's exceeded options can be sold in the spot market to make speculation revenue. Therefore, in this section, we incorporate the option speculation into the portfolio procurement in Section 2 under the stochastic demand and the stochastic spot price. We suppose that the option ordering quantity with option speculation is $q_{2}$. For convenience, we use $\Pi_{2}^{o}\left(q_{2}, D\right)$ to denote the profit from the option contract, and $\Pi_{2}^{s}\left(q_{2}, D, p\right)$ to denote the profit from the spot market and the shortage penalty for lost sales. Under the option speculation, according to the principle of the buyer's profit maximization, we can formulate the optimal portfolio procurement strategy model as the following optimization problem:

$$
\max _{q_{2}} \Pi_{2}=\Pi_{2}^{o}\left(q_{2}, D\right)+\Pi_{2}^{s}\left(q_{2}, D, p\right)
$$

For the concerned model, when the selling season comes, the stochastic demand and the stochastic spot price can be determined. So, one of the following three cases will happen:

Case 1. $0 \leq D<q_{2}+\gamma Q_{s}$, and $p>e$. In this case, the buyer will first execute the options of $q_{2}$ units. If the demand cannot be met, namely, $q_{2} \leq D<q_{2}+\gamma Q_{s}$, the exceeded demand $D-q_{2}$ will be satisfied through the spot market, and if the demand is met, namely, $0 \leq D<q_{2}$, the exceeded options of $q_{2}-D$ units will be sold in the spot market at the spot price $p$ for each unit. That is to say, only when $0 \leq D<q_{2}$ and $p>e$, the option speculation will occur and make speculation revenue. Under this case, we have $\Pi_{2}^{o}\left(q_{2}, D\right)=-b q_{2}+$ $(r-e) \min \left(q_{2}, D\right)+(p-e)\left(q_{2}-D\right)_{+} \quad$ and $\Pi_{2}^{s}\left(q_{2}\right.$, $D, p)=(r-p)\left(D-q_{2}\right)_{+}$. The other two cases are the same as those in Section 2, which are omitted.

From the analysis above, we can see that the buyer's profit for option ordering quantity $q_{2}$ is

$$
\Pi_{2}\left(q_{2}\right)=-b q_{2}+ \begin{cases}(r-e) \min \left(q_{2}, D\right)+(p-e)\left(q_{2}-D\right)_{+}+(r-p)\left(D-q_{2}\right)_{+}, & D<q_{2}+\gamma Q_{s}, p>e, \\ (r-e)\left(D-\gamma Q_{s}\right)_{+}+(r-p) \min \left(\gamma Q_{s}, D\right), & D<q_{2}+\gamma Q_{s}, p \leq e, \\ (r-e) q_{2}+(r-p) \gamma Q_{s}-s\left(D-q_{2}-\gamma Q_{s}\right), & D \geq q_{2}+\gamma Q_{s} .\end{cases}
$$

Since the demand and the spot price are stochastic, to solve problem (10), we compute the expectation of the buy's profit. From this, the buyer's expected profit for ordering quantity $q_{2}$ in the option contract is given as 


$$
\begin{aligned}
E\left[\Pi_{2}\left(q_{2}\right)\right]= & -b q_{2} \\
& +\int_{e}^{r+s}(r-e) f_{2}(y) \mathrm{d} y \int_{0}^{q_{2}} x f_{1}(x) \mathrm{d} x+\int_{e}^{r+s}(r-e) f_{2}(y) \mathrm{d} y \int_{q_{2}}^{q_{2}+\gamma Q_{s}} q_{2} f_{1}(x) \mathrm{d} x \\
& +\int_{e}^{r+s}(r-y) f_{2}(y) \mathrm{d} y \int_{q_{2}}^{q_{2}+\gamma Q_{s}}\left(x-q_{2}\right) f_{1}(x) \mathrm{d} x \\
& +\int_{e}^{r+s}(y-e) f_{2}(y) \mathrm{d} y \int_{0}^{q_{2}}\left(q_{2}-x\right) f_{1}(x) \mathrm{d} x \\
& +\int_{0}^{e}(r-y) f_{2}(y) \mathrm{d} y \int_{0}^{\gamma Q_{s}} x f_{1}(x) \mathrm{d} x+\int_{0}^{e}(r-y) f_{2}(y) \mathrm{d} y \int_{\gamma Q_{s}}^{q_{2}+\gamma Q_{s}} \gamma Q_{s} f_{1}(x) \mathrm{d} x \\
& +\int_{0}^{e}(r-e) f_{2}(y) \mathrm{d} y \int_{\gamma Q_{s}}^{q_{2}+\gamma Q_{s}}\left(x-\gamma Q_{s}\right) f_{1}(x) \mathrm{d} x \\
& +(r-e) \int_{q_{2}+\gamma Q_{s}}^{\infty} q_{2} f_{1}(x) \mathrm{d} x+(r-\bar{p}) \int_{q_{2}+\gamma Q_{s}}^{\infty} \gamma Q_{s} f_{1}(x) \mathrm{d} x-s \int_{q_{2}+\gamma Q_{s}}^{\infty}\left(x-q_{2}-\gamma Q_{s}\right) f_{1}(x) \mathrm{d} x
\end{aligned}
$$

The first term in the right-hand side is the cost of purchasing the options of $q_{2}$ units before the selling season, the second to the fourth items represent retail revenue of the buyer for the case that $0 \leq D<q_{2}+\gamma Q_{s}$ and $p>e$, the fifth item is the speculation revenue from the exceeded options, the sixth to the eighth items represent the retail revenue of the buyer for the case that $0 \leq D<q_{2}+\gamma Q_{s}$ and $p \leq e$, and the last three items represent the retail revenue and shortage cost of the buyer for the case that $D \geq q_{2}+\gamma Q_{s}$.

By maximizing the buyer's profit, we can obtain an optimal ordering policy to the buyer.
Theorem 2. The optimal option ordering quantity $q_{2}^{*}$ with the option speculation to maximize the buyer's expected profit $E\left[\Pi_{2}\left(q_{2}\right)\right]$ satisfies

$$
r-e-b+s-F_{1}\left(q_{2}^{*}+\gamma Q_{s}\right) \int_{e}^{r+s} F_{2}(y) d y=0 .
$$

Proof. For (12), it can be readily computed that

$$
\begin{aligned}
& \frac{\partial E\left[\Pi_{2}\left(q_{2}\right)\right]}{\partial q_{2}}=r-e-b+s-F_{1}\left(q_{2}+\gamma Q_{s}\right) \int_{e}^{r+s} F_{2}(y) \mathrm{d} y, \\
& \frac{\partial^{2} E\left[\Pi_{2}\left(q_{2}\right)\right]}{\partial q_{2}^{2}}=-f_{1}\left(q_{2}+\gamma Q_{s}\right) \int_{e}^{r+s} F_{2}(y) \mathrm{d} y \leq 0,
\end{aligned}
$$

which implies $E\left[\Pi_{2}\left(q_{2}\right)\right]$ is concave in $q_{2}$. From the firstorder optimality condition, we conclude that $E\left[\Pi_{2}\left(q_{2}\right)\right]$ achieves its maximum when $q_{2}^{*}$ satisfies

$$
r-e-b+s-F_{1}\left(q_{2}^{*}+\gamma Q_{s}\right) \int_{e}^{r+s} F_{2}(y) \mathrm{d} y=0 .
$$

Theorems 1 and 2 give the optimal option ordering quantity without and with the option speculation when the spot trading liquidity $\gamma$ is considered, respectively. If we let $\gamma=0$, the optimal option ordering quantity without the option speculation, i.e., the optimal option ordering quantity with the spot trading liquidity, reduces to the optimal option 
ordering quantity in the traditional newsvendor problem. Similar to Corollaries 1 and 2, we have the same results on the optimal option ordering quantity $q_{2}^{*}$ w.r.t. the retail price $r$, the shortage cost $s$, the option purchase price $b$, the option execution price $e$, and the spot trading liquidity $\gamma$, which are omitted herein. Similar to Corollary 3, we have the buyer's maximum expected profit $E\left[\Pi_{2}\left(q_{2}^{*}\right)\right]$ with option speculation is increasing w.r.t. the spot trading liquidity $\gamma$, which is omitted herein.
Theorem 3. The optimal option ordering quantity with the option speculation is larger than that with the spot trading liquidity, i.e., $q_{2}^{*} \geq q_{1}^{*}$.

Proof. From $\int_{e}^{r+s}(y-e) \mathrm{d} F_{2}(y)=r+s-e-\int_{e}^{r+s} F_{2}(y) \mathrm{d} y$ and (4), we can obtain that

$$
F_{1}\left(q_{1}^{*}+\gamma Q_{s}\right) \int_{e}^{r+s} F_{2}(y) \mathrm{d} y+F_{1}\left(q_{1}^{*}\right) \int_{e}^{r+s}(y-e) \mathrm{d} F_{2}(y)=r-e-b+s .
$$

From (13), we can obtain that

$$
F_{1}\left(q_{2}^{*}+\gamma Q_{s}\right) \int_{e}^{r+s} F_{2}(y) d y=r-e-b+s
$$

and then

$$
F_{1}\left(q_{1}^{*}+\gamma Q_{s}\right) \int_{e}^{r+s} F_{2}(y) \mathrm{d} y+F_{1}\left(q_{1}^{*}\right) \int_{e}^{r+s}(y-e) \mathrm{d} F_{2}(y)=F_{1}\left(q_{2}^{*}+\gamma Q_{s}\right) \int_{e}^{r+s} F_{2}(y) \mathrm{d} y .
$$

Since $F_{1}\left(q_{1}^{*}\right) \int_{e}^{r+s}(y-e) \mathrm{d} F_{2}(y) \geq 0, \quad$ we have $F_{1}\left(q_{2}^{*}+\gamma Q_{s}\right) \geq F_{1}\left(q_{1}^{*}+\gamma Q_{s}\right)$. Besides, the distribution function of the demand $F_{1}(\cdot)$ is an increasing function, and then it is obvious that $q_{2}^{*} \geq q_{1}^{*}$.

Since the optimal option ordering quantity with the option speculation is larger than that with the spot trading liquidity, a question then is how the option speculation can influence the expected profit of the buyer. We have the following result to address this issue.

Theorem 4. Define

$$
\begin{aligned}
Z= & \int_{e}^{r+s}(y-e) \mathrm{d} F_{2}(y) \int_{0}^{q_{1}^{*}} F(x) \mathrm{d} x_{1} \\
& -\int_{e}^{r+s}(r+s-y) \mathrm{d} F_{2}(y) \int_{q_{1}^{*}+\gamma Q_{s}}^{q_{2}^{*}+\gamma Q_{s}} F_{1}(x) \mathrm{d} x \\
& -\int_{0}^{e}(r+s-e) \mathrm{d} F_{2}(y) \int_{q_{1}^{*}+\gamma Q_{s}}^{q_{2}^{*}+\gamma Q_{s}} F(x) \mathrm{d} x_{1}
\end{aligned}
$$

when $e+b<r+s+\left(Z /\left(q_{2}^{*}-q_{1}^{*}\right)\right)$, and the buyer's maximum expected profit with the spot trading liquidity is lower than that with the option speculation, i.e., $E\left[\Pi_{1}\left(q_{1}^{*}\right)\right]<E\left[\Pi_{2}\left(q_{2}^{*}\right)\right]$.

When $e+b>r+s+\left(Z /\left(q_{2}^{*}-q_{1}^{*}\right)\right)$, the buyer's maximum expected profit with the spot trading liquidity is larger than that with the option speculation, i.e., $E\left[\Pi_{1}\left(q_{1}^{*}\right)\right]>E\left[\Pi_{2}\left(q_{2}^{*}\right)\right]$.

Proof. For (3) and (12), it can be readily computed that

$$
\begin{aligned}
E[ & \left.\Pi_{2}\left(q_{2}^{*}\right)\right]-E\left[\Pi_{1}\left(q_{1}^{*}\right)\right] \\
= & (r-e-b+s)\left(q_{2}^{*}-q_{1}^{*}\right)+\int_{e}^{r+s}(y-e) \mathrm{d} F_{2}(y) \int_{0}^{q_{1}^{*}} F_{1}(x) \mathrm{d} x \\
& \quad-\int_{e}^{r+s}(r+s-y) \mathrm{d} F_{2}(y) \int_{q_{1}^{*}+\gamma Q_{s}}^{q_{2}^{*}+\gamma Q_{s}} F_{1}(x) \mathrm{d} x-\int_{0}^{e}(r+s-e) \mathrm{d} F_{2}(y) \int_{q_{1}^{*}+\gamma Q_{s}}^{q_{2}^{*}+\gamma Q_{s}} F_{1}(x) \mathrm{d} x .
\end{aligned}
$$


To simplify, define

$$
\begin{aligned}
Z= & \int_{e}^{r+s}(y-e) \mathrm{d} F_{2}(y) \int_{0}^{q_{1}^{*}} F_{1}(x) \mathrm{d} x \\
& -\int_{e}^{r+s}(r+s-y) \mathrm{d} F_{2}(y) \int_{q_{1}^{*}+\gamma Q_{s}}^{q_{2}^{*}+\gamma Q_{s}} F_{1}(x) \mathrm{d} x \\
& -\int_{0}^{e}(r+s-e) \mathrm{d} F_{2}(y) \int_{q_{1}^{*}+\gamma Q_{s}}^{q_{2}^{*}+\gamma Q_{s}} F(x) \mathrm{d} x_{1},
\end{aligned}
$$

and then

$$
E\left[\Pi_{2}\left(q_{2}^{*}\right)\right]-E\left[\Pi_{1}\left(q_{1}^{*}\right)\right]=(r-e-b+s)\left(q_{2}^{*}-q_{1}^{*}\right)+Z .
$$

When $\quad e+b<r+s+\left(Z /\left(q_{2}^{*}-q_{1}^{*}\right)\right)$, it follows $E\left[\Pi_{1}\left(q_{1}^{*}\right)\right]<E\left[\Pi_{2}\left(q_{2}^{*}\right)\right]$.

When $e+b>r+s+\left(Z /\left(q_{2}^{*}-q_{1}^{*}\right)\right)$, it follows $E\left[\Pi_{1}\left(q_{1}^{*}\right)\right]>E\left[\Pi_{2}\left(q_{2}^{*}\right)\right]$.

When $e+b=r+s+\left(Z /\left(q_{2}^{*}-q_{1}^{*}\right)\right)$, it follows $E\left[\Pi_{1}\left(q_{1}^{*}\right)\right]=E\left[\Pi_{2}\left(q_{2}^{*}\right)\right]$.

From the conclusion, we can see that option speculation is unreliable, and the buyer cannot rely excessively on option speculation. When $e+b>r+s+\left(Z /\left(q_{2}^{*}-q_{1}^{*}\right)\right)$, the sum of the option purchase price and option execution price is too high, and the buyer is unlikely to profit from the option speculation. Hence, the buyer should order options without considering the option speculation. To sum up, if $0<e+b<r+s+\left(Z /\left(q_{2}^{*}-q_{1}^{*}\right)\right)$, the buyer should consider option speculation to maximize the expected profit. If $r+s+\left(Z /\left(q_{2}^{*}-q_{1}^{*}\right)\right)<e+b \leq r+s$, the buyer should not consider the option speculation, namely, only consider the spot trading liquidity to maximize the expected profit. If $e+b=r+s+\left(Z /\left(q_{2}^{*}-q_{1}^{*}\right)\right)$, the buyer will have the same maximum expected profit no matter whether the option speculation is considered or not, i.e., $E\left[\Pi_{1}\left(q_{1}^{*}\right)\right]=E\left[\Pi_{2}\left(q_{2}^{*}\right)\right]$.

Corollary 4. If the buyer and the supplier sign the option purchase price $b=\bar{p}-E[\min (e, p)]$, the buyer's maximum expected profit with the spot trading liquidity is lower than that with the option speculation, i.e., $E\left[\Pi_{1}\left(q_{1}^{*}\right)\right] \leq E\left[\Pi_{2}\left(q_{2}^{*}\right)\right]$.

Proof. For (3) and (12), it can be readily computed that

$$
\begin{aligned}
E\left[\Pi_{2}\left(q_{2}^{*}\right)\right]-E\left[\Pi_{1}\left(q_{1}^{*}\right)\right]= & (r-e-b+s)\left(q_{2}^{*}-q_{1}^{*}\right)+\int_{e}^{r+s}(y-e) \mathrm{d} F_{2}(y) \int_{0}^{q_{1}^{*}} F_{1}(x) \mathrm{d} x \\
& -\int_{e}^{r+s}(r+s-y) \mathrm{d} F_{2}(y) \int_{q_{1}^{*}+\gamma Q_{s}}^{q_{2}^{*}+\gamma Q_{s}} F_{1}(x) \mathrm{d} x-\int_{0}^{e}(r+s-e) \mathrm{d} F_{2}(y) \int_{q_{1}^{*}+\gamma Q_{s}}^{q_{2}^{*}+\gamma Q_{s}} F_{1}(x) \mathrm{d} x \\
\geq & (r-e-b+s)\left(q_{2}^{*}-q_{1}^{*}\right)+\int_{e}^{r+s}(y-e) \mathrm{d} F_{2}(y) \int_{0}^{q_{1}^{*}} F_{1}(x) \mathrm{d} x \\
& -\int_{e}^{r+s}(r+s-y) \mathrm{d} F_{2}(y) \int_{q_{1}^{*}+\gamma Q_{s}}^{q_{2}^{*}+\gamma Q_{s}} \mathrm{~d} x-\int_{0}^{e}(r+s-e) \mathrm{d} F_{2}(y) \int_{q_{1}^{*}+\gamma Q_{s}}^{q_{2}^{*}+\gamma Q_{s}} \mathrm{~d} x \\
= & \left(\int_{e}^{r+s}(y-e) \mathrm{d} F_{2}(y)-b\right)\left(q_{2}^{*}-q_{1}^{*}\right)+\int_{e}^{r+s}(y-e) \mathrm{d} F_{2}(y) \int_{0}^{q_{1}^{*}} F_{1}(x) \mathrm{d} x .
\end{aligned}
$$

From $b=\bar{p}-E[\min (e, p)]=\int_{e}^{r+s}(y-e) \mathrm{d} F_{2}(y)$, we can obtain that

$$
E\left[\Pi_{2}\left(q_{2}^{*}\right)\right]-E\left[\Pi_{1}\left(q_{1}^{*}\right)\right] \geq \int_{e}^{r+s}(y-e) \mathrm{d} F_{2}(y) \int_{0}^{q_{1}^{*}} F_{1}(x) \mathrm{d} x \geq 0 .
$$

From the conclusion, we can see that if the buyer and the supplier sign the option purchase price $b=\bar{p}-E[\min (e, p)]$, the buyer should consider the option speculation to maximize the expected profit. The option pricing formula $b=\bar{p}-E[\min (e, p)]$ ensures that the option purchase price is neither too high nor too low, which is a fair price for both the buyer and the supplier $[32,33]$.

\section{Numerical Results}

In this section, we provide some numerical examples to illustrate the validity of our research.
Example 1. Suppose that the demand $D$ subjects to the uniform distribution $U[0,1000]$, and the spot price $p$ subjects to the uniform distribution $U[6, r+s]$. For the given parameters, we solve the optimal option purchase quantities $q_{1}^{*}$ and $q_{2}^{*}$ and give sensitivity analysis on different parameters.

For $s=2, \gamma=0.5, Q_{s}=400, e=9, \quad$ and $b=1.5$, we compute the optimal option purchase quantities $q_{1}^{*}$ and $q_{2}^{*}$ with different retail price $r \in[11,13]$ in Figure 1, which shows that both the optimal option ordering quantities $q_{1}^{*}$ and $q_{2}^{*}$ are increasing w.r.t. the retail price $r$. It is also verified that the optimal option ordering quantity $q_{2}^{*}$ is larger than $q_{1}^{*}$ under different retail price $r$.

For $r=12, \gamma=0.5, Q_{s}=400, e=9$, and $b=1.5$, we compute the optimal option ordering quantities $q_{1}^{*}$ and $q_{2}^{*}$ with different shortage cost $s \in[1,3]$ in Figure 2. Figure 2 shows that both the optimal option ordering quantities $q_{1}^{*}$ and $q_{2}^{*}$ are increasing w.r.t. the shortage cost $s$. It is also 


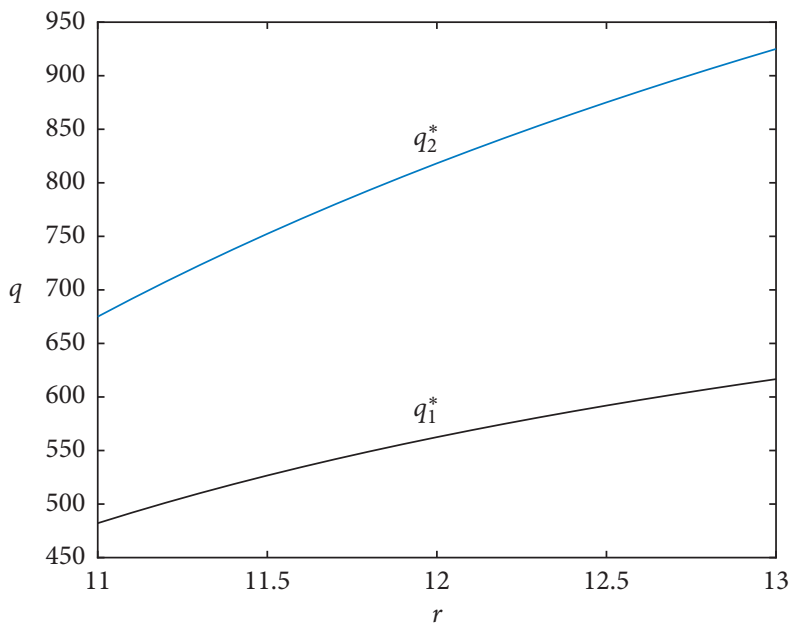

FIgURE 1: Optimal option ordering quantities $q_{1}^{*}$ and $q_{2}^{*}$ with different retail price $r$.

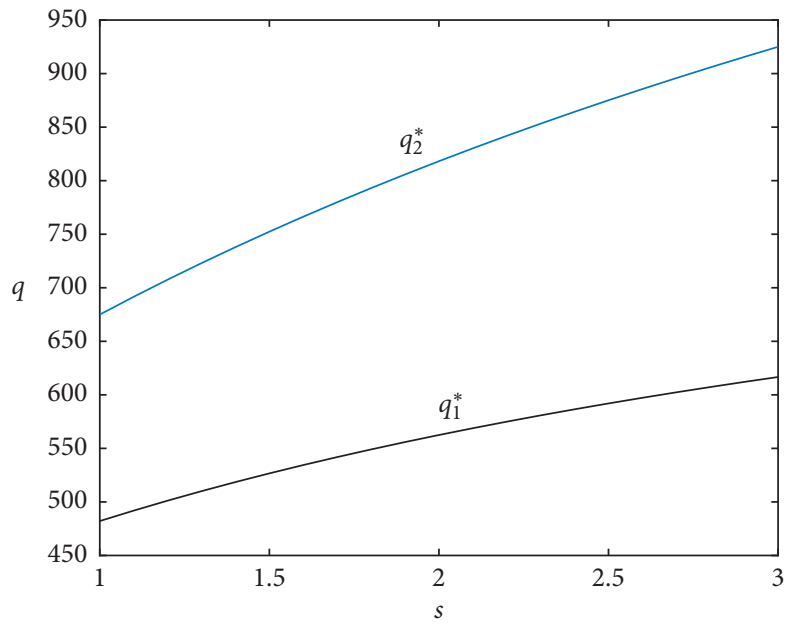

Figure 2: Optimal option ordering quantities $q_{1}^{*}$ and $q_{2}^{*}$ with different shortage cost $s$.

verified that the optimal option ordering quantity $q_{2}^{*}$ is larger than $q_{1}^{*}$ under different shortage cost.

For $r=12, \gamma=0.5, Q_{s}=400, e=9$, and $s=2$, we compute the optimal option ordering quantities $q_{1}^{*}$ and $q_{2}^{*}$ with different option purchase price $b \in[0.5,2.5]$ in Figure 3 . Figure 3 shows that both the optimal option ordering quantities $q_{1}^{*}$ and $q_{2}^{*}$ are decreasing w.r.t. the option purchase price $b$. It is also verified that the optimal option ordering quantity $q_{2}^{*}$ is larger than $q_{1}^{*}$ under different option purchase price $b$.

For $r=12, \gamma=0.5, Q_{s}=400, b=1.5$, and $s=2$, we compute the optimal option ordering quantities $q_{1}^{*}$ and $q_{2}^{*}$ with different option execution price $e \in[8,10]$ in Figure 4 . Figure 4 shows that both the optimal option ordering quantities $q_{1}^{*}$ and $q_{2}^{*}$ are decreasing w.r.t. the option execution price $e$. It is also verified that the optimal option ordering quantity $q_{2}^{*}$ is larger than $q_{1}^{*}$ under different option execution price $e$.

For $r=12, e=9, Q_{s}=400, b=1.5$, and $s=2$, we compute the optimal option ordering quantities $q_{1}^{*}$ and $q_{2}^{*}$ with different spot trading liquidity $\gamma \in[0,1]$ in Figure 5. Figure 5 shows that both the optimal option ordering quantities $q_{1}^{*}$ and $q_{2}^{*}$ are decreasing w.r.t. the spot trading liquidity $\gamma$. It is also verified that the optimal option ordering quantity $q_{2}^{*}$ is larger than $q_{1}^{*}$ under different spot trading liquidity $\gamma$. The red line indicates the optimal option ordering quantity in the traditional newsvendor problem, where $\gamma=0$.

For $r=12, e=9, Q_{s}=400, b=1.5$, and $s=2$, we compute the expected profit utilities $E\left[\prod_{1}\left(q_{1}^{*}\right)\right]$ and $E\left[\prod_{2}\left(q_{2}^{*}\right)\right]$ with different spot trading liquidity $\gamma \in[0,1]$ in Figure 6 . Figure 6 shows that both the expected profit utilities $E\left[\Pi_{1}\left(q_{1}^{*}\right)\right]$ and $E\left[\Pi_{2}\left(q_{2}^{*}\right)\right]$ are increasing w.r.t. the spot 


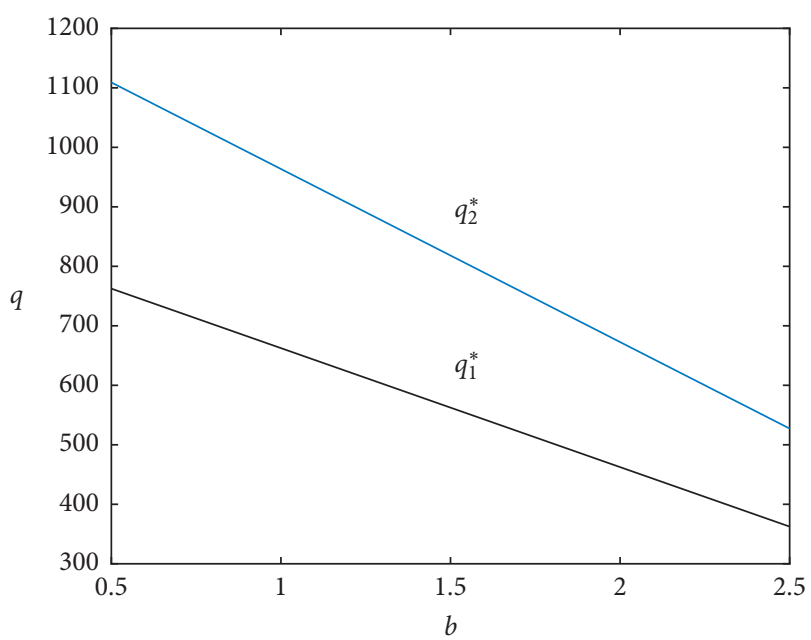

FIGURE 3: Optimal option ordering quantities $q_{1}^{*}$ and $q_{2}^{*}$ with different option purchase price $b$.

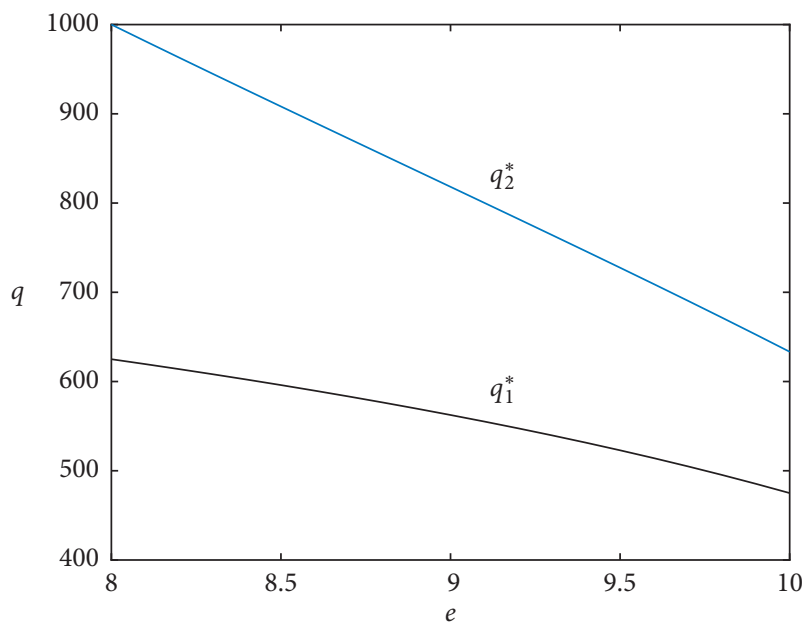

FIgURE 4: Optimal option ordering quantities $q_{1}^{*}$ and $q_{2}^{*}$ with different option execution price $e$.

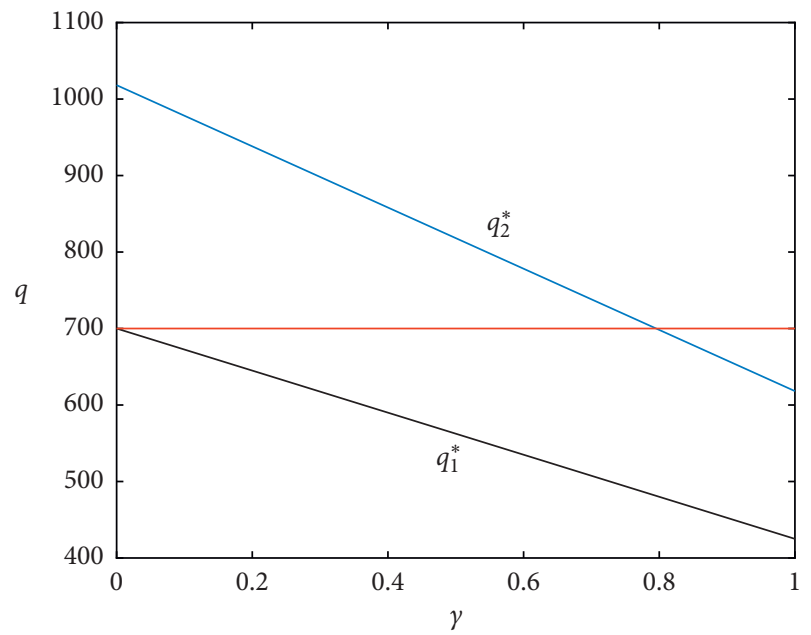

FIGURE 5: Optimal option ordering quantities $q_{1}^{*}$ and $q_{2}^{*}$ with different spot trading liquidity $\gamma$.

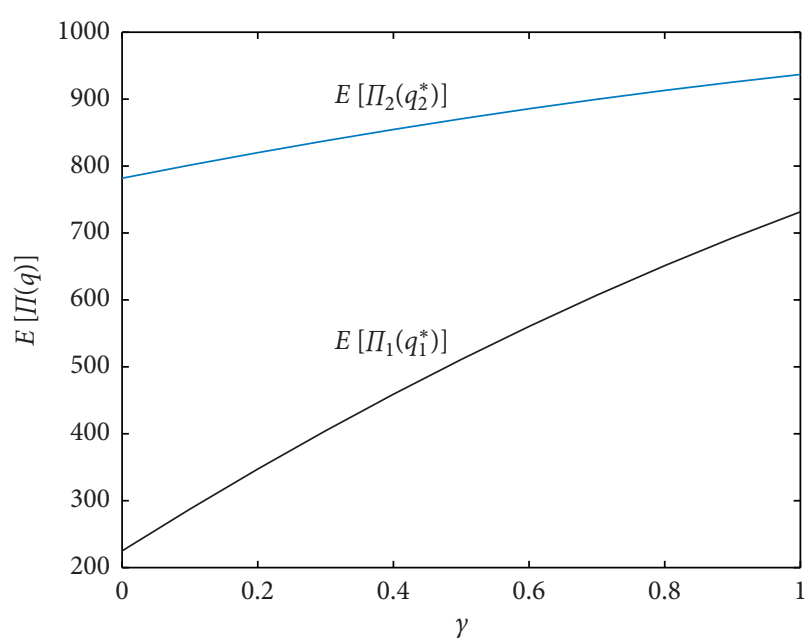

FIgURE 6: Expected profit utilities $E\left[\prod_{1}\left(q_{1}^{*}\right)\right]$ and $E\left[\prod_{2}\left(q_{2}^{*}\right)\right]$ with different spot trading liquidity $\gamma$.

trading liquidity $\gamma$. It is also verified that when $e+b<r+s+\left(Z /\left(q_{2}^{*}-q_{1}^{*}\right)\right)$, the maximum expected profit without the option speculation is lower than that with the option speculation under different spot trading liquidity $\gamma$.

\section{Conclusions}

This paper investigated the portfolio procurement with the spot trading liquidity or the option speculation under the stochastic demand and the stochastic spot price. For these scenarios, two optimal portfolio procurement strategy models were established to maximize the buyer's profit, respectively. Based on the buyer's cost-benefit analysis, a global optimizing solution method for each model was obtained. Then, the role of the spot trading liquidity and option speculation in buyer's expected profit was analyzed. Furthermore, the cost threshold and option pricing formula were obtained, which provided a decision basis for the buyer. Numerical experiments were carried out to illustrate the validity of our research.

By using the mathematical foundation of probability, our research is quite generic and is essentially applicable to other industrial sectors with multiple sourcing and perishable products. In that sense, our research enriches the portfolio procurement literature in a broader context. Some extensions of our research are as follows. One possible extension is to consider the portfolio of a long-term contract and an option contract under a spot market. Another possible extension is to incorporate risk preference of the buyer into this study, which is a more interesting issue.

\section{Data Availability}

The data used to support the findings of this study are available from the corresponding author upon request.

\section{Conflicts of Interest}

The authors declare that there are no conflicts of interests regarding the publication of this paper. 


\section{Authors' Contributions}

Each author equally contributed to this paper and read and approved the final manuscript.

\section{Acknowledgments}

This project was supported by the National Natural Science Foundation of China (12071250 and 12071249).

\section{References}

[1] J. Xu, G. Feng, W. Jiang, and S. Wang, "Optimal procurement of long-term contracts in the presence of imperfect spot market," Omega, vol. 52, pp. 42-52, 2015.

[2] R. W. Seifert, U. W. Thonemann, and W. H. Hausman, "Optimal procurement strategies for online spot markets," European Journal of Operational Research, vol. 152, no. 3, pp. 781-799, 2004.

[3] Ç. Haksöz and S. Seshadri, "Supply chain operations in the presence of a spot market: a review with discussion," Journal of the Operational Research Society, vol. 58, no. 11, pp. 1412-1429, 2007.

[4] V. Nagali, J. Hwang, D. Sanghera et al., "Procurement risk management (PRM) at hewlett-packard company," Interfaces, vol. 38, no. 1, pp. 51-60, 2008.

[5] B. Peleg and H. Lee, "Short-term E-procurement strategies versus long-term contracts," Production and Operations Management, vol. 11, no. 4, pp. 458-479, 2002.

[6] S.-L. Chen and C.-L. Liu, "Procurement strategies in the presence of the spot market-an analytical framework," Production Planning \& Control, vol. 18, no. 4, pp. 297-309, 2007.

[7] A. Goel and G. J. Gutierrez, "Multiechelon procurement and distribution policies for traded commodities," Management Science, vol. 57, no. 12, pp. 2228-2244, 2011.

[8] C. K. M. Lee, D. Lin, and R. Pasari, "Strategic procurement from forward contract and spot market," Industrial Management \& Data Systems, vol. 114, no. 5, pp. 778-796, 2014.

[9] Y. Chen, W. Xue, and J. Yang, "Technical note-optimal inventory policy in the presence of a long-term supplier and a spot market," Operations Research, vol. 61, no. 1, pp. 88-97, 2013.

[10] N. Adilov, "Strategic use of forward contracts and capacity constraints," International Journal of Industrial Organization, vol. 30, no. 2, pp. 164-173, 2012.

[11] K. Inderfurth, P. Kelle, and R. Kleber, "Dual sourcing using capacity reservation and spot market: optimal procurement policy and heuristic parameter determination," European Journal of Operational Research, vol. 225, no. 2, pp. 298-309, 2013.

[12] X. Gou, Z. Xu, and F. Herrera, "Consensus reaching process for large-scale group decision making with double hierarchy hesitant fuzzy linguistic preference relations," KnowledgeBased Systems, vol. 157, pp. 20-33, 2018.

[13] H. Liao, X. Mi, and Z. Xu, "A survey of decision-making methods with probabilistic linguistic information: bibliometrics, preliminaries, methodologies, applications and future directions," Fuzzy Optimization and Decision Making, vol. 19, no. 1, pp. 81-134, 2020.

[14] C. Wang, H. Chen, Y. Wang, and G. Zhou, "On copositiveness identification of partially symmetric rectangular tensors," Journal of Computational and Applied Mathematics, vol. 372, Article ID 112678, 2020.

[15] W. Wang, H. Chen, and Y. Wang, "A new C-eigenvalue interval for piezoelectric-type tensors," Applied Mathematics Letters, vol. 100, p. 106035, 2020.
[16] Y. Wang, X. Sun, and F. Meng, "On the conditional and partial trade credit policy with capital constraints: a Stackelberg model," Applied Mathematical Modelling, vol. 40, no. 1, pp. 1-18, 2016.

[17] Y. Wang, W. Xing, W. Xing, and H. Gao, "Optimal ordering policy for inventory mechanism with a stochastic short-term price discount," Journal of Industrial \& Management Optimization, vol. 16, no. 3, pp. 1187-1202, 2020.

[18] Q. Fu, C.-Y. Lee, and C.-P. Teo, "Procurement management using option contracts: random spot price and the portfolio effect," IIE Transactions, vol. 42, no. 11, pp. 793-811, 2010.

[19] P. P.-E. Pei, D. Simchi-Levi, and T. I. Tunca, "Sourcing flexibility, spot trading, and procurement contract structure," Operations Research, vol. 59, no. 3, pp. 578-601, 2011.

[20] Y. Zhao, T.-M. Choi, T. C. E. Cheng, and S. Wang, "Supply option contracts with spot market and demand information updating," European Journal of Operational Research, vol. 266, no. 3, pp. 1062-1071, 2018.

[21] Y. Merzifonluoglu, "Risk averse supply portfolio selection with supply, demand and spot market volatility," Omega, vol. 57, pp. 40-53, 2015.

[22] Y. Merzifonluoglu, "Integrated demand and procurement portfolio management with spot market volatility and option contracts," European Journal of Operational Research, vol. 258, no. 1, pp. 181-192, 2017.

[23] J. Luo and X. Chen, "Risk hedging via option contracts in a random yield supply chain," Annals of Operations Research, vol. 257, no. 1-2, pp. 697-719, 2017.

[24] C.-Y. Lee, X. Li, and Y. Xie, "Procurement risk management using capacitated option contracts with fixed ordering costs," IIE Transactions, vol. 45, no. 8, pp. 845-864, 2013.

[25] N. Wan and X. Chen, "Multi-period dual-sourcing replenishment problem with option contracts and a spot market," Industrial Management \& Data Systems, vol. 118, no. 4, pp. 782-805, 2018.

[26] E. Anderson, B. Chen, and L. Shao, "Supplier competition with option contracts for discrete blocks of capacity," Operations Research, vol. 65, no. 4, pp. 952-967, 2017.

[27] H. Chen, Y. Wang, and G. Zhou, "High-order sum-of-squares structured tensors: theory and applications," Frontiers of Mathematics in China, vol. 15, no. 2, pp. 255-284, 2020.

[28] M. Dong and H. Chen, "Geometry of the copositive tensor cone and its dual," Asia-Pacific Journal of Operational Research, vol. 37, no. 4, Article ID 2040008, 2020.

[29] X. Gou, H. Liao, Z. Xu, R. Min, and F. Herrera, "Group decision making with double hierarchy hesitant fuzzy linguistic preference relations: consistency based measures, index and repairing algorithms and decision model," Information Sciences, vol. 489, pp. 93-112, 2019.

[30] J. Namdar, X. Li, R. Sawhney, and N. Pradhan, "Supply chain resilience for single and multiple sourcing in the presence of disruption risks," International Journal of Production Research, vol. 56, no. 6, pp. 2339-2360, 2018.

[31] Z. Xu and X. Gou, "An overview of interval-valued intuitionistic fuzzy information aggregations and applications," Granular Computing, vol. 2, no. 1, pp. 13-39, 2017.

[32] P. Aggarwal and R. Ganeshan, "Using risk-management tools on B2Bs: an exploratory investigation," International Journal of Production Economics, vol. 108, no. 1-2, pp. 2-7, 2007.

[33] R. Ganeshan, T. Boone, and P. Aggarwal, "Optimal procurement portfolios when using B2Bs: a model and analysis," International Journal of Production Economics, vol. 118, no. 1, pp. 146-151, 2009. 